\title{
Analisis Literasi Lingkungan dalam Buku Teks Pelajaran IPA SMP Kurikulum 2013
}

\author{
Dinda Rachmawati*, Suroso Mukti Leksono, Lukman Nulhakim \\ Program Studi Pendidikan IPA, FKIP, Universitas Sultan Ageng Tirtayasa \\ *Email: dindarch@gmail.com \\ DOI: https://doi.org/10.33369/pendipa.6.1.88-97
}

\begin{abstract}
The aims of this study was to analyze the components of environmental literacy in junior high school science textbooks curriculum 2013 published by the Ministry of Education and Culture VII, VIII and IX grade. The research method is descriptive qualitative with a content analysis approach. The main instrument for data collecting is the document content observation sheet. For data analysis, Miles and huberman's theory has been used. The results showed that the components of environmental literacy is not well covered in $n$ junior high school science textbooks curriculum 2013 published by the Ministry of Education and Culture because all components of environmental literacy did not receive the same attention. Environmental literacy components that get attention in junior high school science textbooks such as knowledge of natural history and ecology, knowledge of environmental issues and problem, and cognitive skills. While the other components not enough attention, namely social-political-economic knowledge, affect and additional determinants of environmentally responsible behavior (ERB), and environmentally responsible behavior (ERB) can be developed by integrating environmental content into chapters in the science textbooks.
\end{abstract}

Keywords: Environmental Literacy; Science Textbooks; Junior High School; Curriculum 2013.

\begin{abstract}
ABSTRAK
Penelitian ini bertujuan untuk menganalisis cakupan komponen literasi lingkungan dalam buku teks pelajaran IPA SMP Kurikulum 2013 Terbitan Kemendikbud Kelas VII, VIII dan IX. Metode yang digunakan pada penelitian ini adalah kualitatif deskriptif dengan pendekatan teknik analisis isi. Instrumen yang digunakan adalah lembar observasi isi dokumen. Adapun teknik analisis data penelitian ini yaitu menggunakan teori Miles dan Huberman. Hasil penelitian menunjukkan komponen literasi lingkungan belum tercakup dengan baik dalam buku teks pelajaran IPA SMP Kurikulum 2013 Terbitan Kemendikbud karena tidak semua mendapat perhatian yang sama. Komponen literasi lingkungan yang mendapat perhatian pada buku teks pelajaran IPA SMP Kurikulum 2013 yaitu pengetahuan ekologi dan sejarah alam, pengetahuan masalah dan isu lingkungan, serta keterampilan kognitif. Adapun komponen lainnya yang kurang mendapat perhatian yaitu pengetahuan sosial-politik-ekonomi, afeksi dan faktorfaktor yang mempengaruhi perilaku bertanggung jawab terhadap lingkungan, serta perilaku bertanggung jawab terhadap lingkungan, masih dapat dikembangkan dengan mengintegrasikan konten lingkungan ke dalam bab-bab pada buku IPA SMP Kurikulum 2013 Terbitan Kemendikbud.
\end{abstract}

Kata kunci: Literasi Lingkungan; Buku Teks Pelajaran IPA; SMP; Kurikulum 2013.

\section{PENDAHULUAN}

Penurunan kualitas lingkungan umumnya disebabkan oleh faktor alam dan manusia. Namun minimnya kesadaran dan tanggung jawab manusia menjadi faktor yang membawa pengaruh lebih besar dalam peningkatan isu lingkungan. Menurut Karimzadegan \& Meiboudi (2012) akibat dari kondisi lingkungan yang semakin memprihatikan, pelestarian lingkungan hidup menjadi perhatian dunia. Beberapa Negara 
menggagas upaya mencegah kerusakan alam dan perubahan iklim yang diajukan kepada Perserikatan Bangsa-Bangsa (PBB), sehingga puncaknya adalah diadakan Konferensi Internasional yang ditujukan membahas masalah lingkungan dalam perspektif global pada tahun 1972 di Stockholm.

Upaya pelestarian tidak dapat dilakukan jika manusianya tidak memiliki kesadaran dan tanggung jawab terhadap lingkungan (Zulfa, dkk., 2016). Sikap sadar seseorang untuk menjaga keseimbangan lingkungan disebut dengan istilah literasi lingkungan (Rahmah, dkk., 2019). Istilah literasi lingkungan juga didefinisikan sebagai kemampuan untuk memahami dan menafsirkan kondisi lingkungan sehingga mampu mengambil tindakan tepat untuk memperbaiki, mempertahankan dan meningkatkan kualitas lingkungan (Tuncer, et al., 2009).

Menurut Simmons dalam Karimzadegan \& Meiboudi (2012), literasi lingkungan memiliki enam komponen yaitu sebagai berikut.

1. Pengetahuan ekologi dan sejarah alam adalah pengetahuan tentang konsep utama ekologi, termasuk pemahaman tentang kerja dari sistem alam serta interaksinya sistem sosial.

2. Pengetahuan masalah dan isu lingkungan adalah pengetahuan tentang masalah lingkungan yang diakibatkan oleh interaksi manusia terhadap lingkungan, serta pengetahuan terkait solusi alternatif untuk menyelesaikan masalah.

3. Pengetahuan sosial-politik-ekonomi adalah pengetahuan tentang hubungan antara kepercayaan, sistem sosial masyarakat, sistem politik, sistem ekonomi dan lainnya dengan nilai-nilai lingkungan dari berbagai budaya ditinjau dari perspektif ekologi.

4. Keterampilan kognitif adalah kumpulan keterampilan dan kemampuan yang dapat diimplementasikan dalam dunia nyata untuk tujuan tertentu.

5. Afeksi dan faktor-faktor yang mempengaruhi perilaku bertanggung jawab terhadap lingkungan adalah faktor-faktor individu yang memungkinkan untuk merefleksikan masalah lingkungan di tingkat intrapersonal dan menindakinya jika mereka menilai masalah tersebut perlu diambil tindakan.
6. Perilaku bertanggung jawab terhadap lingkungan adalah tindakan yang mengharuskan individu untuk menunjukkan partisipasi aktif terhadap lingkungan.

Salah satu upaya untuk mengembangkan kecakapan literasi lingkungan dapat dilakukan melalui pendidikan formal. Reis, GuimaraesIosif \& Reis (2009) menjelaskan bahwa sistem yang dimiliki pendidikan formal yaitu sekolah mampu menginduksi komponen yang mendukung kecakapan literasi lingkungan, diantaranya pengetahuan, keterampilan, sikap maupun tindakan. Srbinovski, Erdogan, \& Ismaili (2010) mengungkapkan bahwa literasi lingkungan dipahami sebagai hasil utama dari pendidikan lingkungan. Menurut Setyowati, dkk., (2014) peranan pendidikan lingkungan di sekolah dapat memunculkan kesadaran dan tanggung jawab terhadap lingkungan.

Pendidikan lingkungan di Indonesia, bukan mata pelajaran khusus, sehingga konten literasi lingkungan harus diintegrasikan dalam mata pelajaran. Menurut Srbinovskia, Erdogan, \& Ismaili (2010) fondasi literasi lingkungan ditekankan melalui mata pelajaran Ilmu Pengetahuan Alam. Kusumaningrum (2018) menjelaskan bahwa IPA dapat menjadi fondasi untuk mengembangkan kecakapan literasi lingkungan karena membahas segala aktivitas manusia berhubungan erat dengan alam.

Upaya pengintegrasian literasi lingkungan dalam pendidikan di Indonesia sebenarnya sudah ada, beberapa sekolah di Indonesia seperti di Kota Tangerang Selatan yang menjalin kerja sama dengan Indonesia Education Promoting Foundation (IEPF) dan Japan International Cooperation Agency (JICA) dalam merencanakan kurikulum pendidikan lingkungan hidup namun dalam pengembangannya masih menggunakan standar kompetensi seperti pada Standar Isi KTSP dan bukan berdasarkan Kompetensi Inti Kurikulum 2013 (Herlanti, 2016). Berdasarkan hal tersebut upaya pengintegrasian literasi lingkungan di Indonesia belum terlaksana dengan baik.

Penerapan Pendidikan lingkungan dalam mengembangkan kecakapan literasi lingkungan salah satunya dapat diupayakan melalui buku teks pelajaran yang memuat komponen literasi lingkungan. Menurut Karimzadegan \& Meiboudi (2012) pembelajaran IPA sangat didukung 
dengan bahan ajar berupa buku teks pelajaran. Nilai-nilai pelestarian lingkungan penting diintegrasikan ke dalam buku teks pelajaran karena dapat meningkatkan kesadaran lingkungan. Oleh karena itu, kegiatan analisis buku teks pelajaran IPA SMP Kurikulum 2013 Terbitan Kemendikbud penting dilakukan untuk mengeksplor apakah buku teks pelajaran yang digunakan sudah memenuhi komponen literasi lingkungan sehingga mampu memfasilitasi untuk dikembangkannya kecakapan literasi lingkungan siswa.

\section{METODE PENELITIAN}

Metode yang digunakan pada penelitian ini adalah kualitatif deskriptif berpendekatan analisis isi. Penelitian dilakukan pada bulan September-Desember 2020 di Laboratorium Pendidikan IPA, FKIP, Universitas Sultan Ageng Tirtayasa. Objek yang menjadi sasaran penelitian ini adalah konten pada buku teks pelajaran IPA SMP Kurikulum 2013 Terbitan Kemendikbud Kelas VII, VIII dan IX. Instrumen yang digunakan dalam penelitian ini adalah lembar observasi buku yang diadaptasi dari tabel hasil analisis Karimzadegan \& Meiboudi (2012). Instrumen ini digunakan sebagai alat untuk menjaring cakupan komponen literasi lingkungan dalam buku teks pelajaran IPA SMP Kurikulum 2013.

Tabel 1. Cakupan Komponen Literasi Lingkungan dalam Buku Teks Pelajaran IPA SMP Kurikulum 2013 Terbitan Kemendikbud

\begin{tabular}{|c|c|c|c|c|c|c|c|}
\hline & \multirow[b]{2}{*}{$\begin{array}{l}\text { Komponen dan } \\
\text { Sub-Komponen }\end{array}$} & \multicolumn{2}{|c|}{ Kelas VII } & \multicolumn{2}{|c|}{ Kelas VIII } & \multicolumn{2}{|c|}{ Kelas IX } \\
\hline & & $\begin{array}{c}\text { Semester } \\
\text { I }\end{array}$ & $\begin{array}{l}\text { Semester } \\
\text { II }\end{array}$ & $\begin{array}{c}\text { Semester } \\
\text { I }\end{array}$ & $\begin{array}{l}\text { Semester } \\
\text { II }\end{array}$ & $\begin{array}{c}\text { Semester } \\
\text { I }\end{array}$ & $\begin{array}{l}\text { Semester } \\
\text { II }\end{array}$ \\
\hline \multicolumn{8}{|c|}{ Komponen Pengetahuan Ekologi dan Sejarah Alam } \\
\hline 1 & Spesies dan populasi & $\sqrt{ }$ & $\sqrt{ }$ & $\sqrt{ }$ & $\sqrt{ }$ & $\sqrt{ }$ & $\sqrt{ }$ \\
\hline 2 & Habitat dan lingkungan & $\sqrt{ }$ & $\sqrt{ }$ & $\sqrt{ }$ & $\sqrt{ }$ & $\sqrt{ }$ & $\sqrt{ }$ \\
\hline 3 & Komunitas dan interaksi & $\sqrt{ }$ & $\sqrt{ }$ & $\sqrt{ }$ & $\sqrt{ }$ & $\sqrt{ }$ & $\sqrt{ }$ \\
\hline 4 & $\begin{array}{l}\text { Abiotik dan siklus } \\
\text { materi }\end{array}$ & $\sqrt{ }$ & $\sqrt{ }$ & $\sqrt{ }$ & $\sqrt{ }$ & $\sqrt{ }$ & $\sqrt{ }$ \\
\hline 5 & Ekosistem dan bioma & $\sqrt{1}$ & $\sqrt{1}$ & - & - & $\sqrt{1}$ & $\sqrt{1}$ \\
\hline 6 & Sistem alam dan sosial & $\sqrt{ }$ & $\sqrt{ }$ & $\sqrt{ }$ & - & $\sqrt{ }$ & $\sqrt{ }$ \\
\hline 7 & $\begin{array}{l}\text { Sejarah fisik dan } \\
\text { biologi }\end{array}$ & - & $\sqrt{ }$ & - & - & - & $\sqrt{ }$ \\
\hline $\mathbf{B}$ & \multicolumn{7}{|c|}{ Komponen Pengetahuan Masalah dan Isu Lingkungan } \\
\hline 1 & $\begin{array}{l}\text { Risiko, toksikologi dan } \\
\text { kesehatan manusia }\end{array}$ & $\sqrt{ }$ & $\sqrt{ }$ & $\sqrt{ }$ & $\sqrt{ }$ & $\sqrt{ }$ & $\sqrt{ }$ \\
\hline 2 & Masalah biofisik & $\sqrt{ }$ & $\sqrt{ }$ & - & - & $\sqrt{ }$ & $\sqrt{ }$ \\
\hline
\end{tabular}




\begin{tabular}{|c|c|c|c|c|c|c|c|}
\hline & \multirow[b]{2}{*}{$\begin{array}{l}\text { Komponen dan } \\
\text { Sub-Komponen }\end{array}$} & \multicolumn{2}{|c|}{ Kelas VII } & \multicolumn{2}{|c|}{ Kelas VIII } & \multicolumn{2}{|c|}{ Kelas IX } \\
\hline & & $\begin{array}{c}\text { Semester } \\
\text { I }\end{array}$ & $\begin{array}{c}\text { Semester } \\
\text { II }\end{array}$ & $\begin{array}{c}\text { Semester } \\
\text { I }\end{array}$ & $\begin{array}{l}\text { Semester } \\
\text { II }\end{array}$ & $\begin{array}{c}\text { Semester } \\
\text { I }\end{array}$ & $\begin{array}{l}\text { Semester } \\
\text { II }\end{array}$ \\
\hline 3 & Penyebab masalah & $\sqrt{ }$ & $\sqrt{ }$ & - & - & $\sqrt{ }$ & $\sqrt{ }$ \\
\hline 4 & Isu sosial politik & - & - & - & - & - & - \\
\hline 5 & Penyebab isu & $\sqrt{ }$ & $\sqrt{ }$ & - & - & $\sqrt{ }$ & $\sqrt{ }$ \\
\hline 6 & $\begin{array}{l}\text { Efek dari masalah dan } \\
\text { isu }\end{array}$ & $\sqrt{ }$ & $\sqrt{ }$ & $\sqrt{ }$ & $\sqrt{ }$ & $\sqrt{ }$ & $\sqrt{ }$ \\
\hline 7 & Bencana alam & - & $\sqrt{ }$ & - & - & - & - \\
\hline 8 & $\begin{array}{l}\text { Solusi dan tindakan } \\
\text { alternatif }\end{array}$ & $\sqrt{ }$ & $\sqrt{ }$ & - & - & $\sqrt{ }$ & $\sqrt{ }$ \\
\hline $\mathrm{C}$ & \multicolumn{7}{|c|}{ Komponen Pengetahuan Sosial-Politik-Ekonomi } \\
\hline 1 & $\begin{array}{l}\text { Nilai dan aktivitas } \\
\text { budaya }\end{array}$ & - & - & - & - & - & - \\
\hline 2 & $\begin{array}{l}\text { Nilai dan aktivitas } \\
\text { ekonomi }\end{array}$ & - & $\sqrt{ }$ & - & - & $\sqrt{ }$ & - \\
\hline 3 & $\begin{array}{l}\text { Sistem sosial } \\
\text { masyarakat }\end{array}$ & $\sqrt{ }$ & $\sqrt{ }$ & $\sqrt{ }$ & - & - & $\sqrt{ }$ \\
\hline 4 & $\begin{array}{l}\text { Sistem pemerintahan } \\
\text { dan politik }\end{array}$ & - & - & - & - & - & - \\
\hline 5 & Pola geografi & - & $\sqrt{ }$ & - & - & - & - \\
\hline 6 & Partisipasi warga negara & $\sqrt{ }$ & $\sqrt{ }$ & - & - & $\sqrt{ }$ & $\sqrt{ }$ \\
\hline D & \multicolumn{7}{|c|}{ Komponen Keterampilan Kognitif } \\
\hline 1 & $\begin{array}{l}\text { Keterampilan } \\
\text { mengidentifikasi } \\
\text { masalah dan isu }\end{array}$ & $\sqrt{ }$ & $\sqrt{ }$ & - & $\sqrt{ }$ & - & - \\
\hline 2 & $\begin{array}{l}\text { Keterampilan } \\
\text { menganalisis isu }\end{array}$ & $\sqrt{ }$ & $\sqrt{ }$ & - & - & $\sqrt{ }$ & $\sqrt{ }$ \\
\hline 3 & Keterampilan bertanya & $\sqrt{ }$ & $\sqrt{ }$ & - & - & - & - \\
\hline 4 & $\begin{array}{l}\text { Keterampilan } \\
\text { mengumpulkan data }\end{array}$ & $\sqrt{ }$ & $\sqrt{ }$ & $\sqrt{ }$ & $\sqrt{ }$ & $\sqrt{ }$ & $\sqrt{ }$ \\
\hline 5 & $\begin{array}{l}\text { Keterampilan } \\
\text { menganalisis data }\end{array}$ & $\sqrt{ }$ & $\sqrt{ }$ & $\sqrt{ }$ & $\sqrt{ }$ & $\sqrt{ }$ & $\sqrt{ }$ \\
\hline 6 & Keterampilan bertindak & $\sqrt{ }$ & $\sqrt{ }$ & $\sqrt{ }$ & $\sqrt{ }$ & $\sqrt{ }$ & $\sqrt{ }$ \\
\hline $\mathbf{E}$ & \multicolumn{7}{|c|}{$\begin{array}{l}\text { Komponen Afeksi dan Faktor-Faktor Yang Memengaruhi Perilaku Bertanggung Jawab } \\
\text { Terhadap Lingkungan }\end{array}$} \\
\hline 1 & $\begin{array}{l}\text { Kepekaan dan } \\
\text { kepedulian terhadap } \\
\text { lingkungan }\end{array}$ & - & $\sqrt{ }$ & $\sqrt{ }$ & $\sqrt{ }$ & $\sqrt{ }$ & $\sqrt{ }$ \\
\hline 2 & Sikap lingkungan & $\sqrt{ }$ & - & $\sqrt{ }$ & $\sqrt{ }$ & $\sqrt{ }$ & $\sqrt{ }$ \\
\hline 3 & Nilai-nilai lingkungan & - & - & $\sqrt{ }$ & - & - & $\sqrt{ }$ \\
\hline 4 & $\begin{array}{l}\text { Pertimbangan moral } \\
\text { dan etika }\end{array}$ & - & - & - & - & - & - \\
\hline 5 & Lokus kendali & - & $\sqrt{ }$ & - & - & - & - \\
\hline 6 & Tanggung jawab pribadi & - & $\sqrt{ }$ & - & $\sqrt{ }$ & $\sqrt{ }$ & $\sqrt{ }$ \\
\hline 7 & $\begin{array}{l}\text { Kemauan/ } \\
\text { motivasi/niat untuk } \\
\text { bertindak }\end{array}$ & - & - & - & - & - & - \\
\hline $\mathrm{F}$ & Komponen Perilaku B & ggu & b Te & Lin & & & \\
\hline
\end{tabular}




\begin{tabular}{|c|c|c|c|c|c|c|c|}
\hline & \multirow[b]{2}{*}{$\begin{array}{l}\text { Komponen dan } \\
\text { Sub-Komponen }\end{array}$} & \multicolumn{2}{|c|}{ Kelas VII } & \multicolumn{2}{|c|}{ Kelas VIII } & \multicolumn{2}{|c|}{ Kelas IX } \\
\hline & & $\begin{array}{c}\text { Semester } \\
\text { I }\end{array}$ & $\begin{array}{l}\text { Semester } \\
\text { II }\end{array}$ & $\begin{array}{c}\text { Semester } \\
\text { I }\end{array}$ & $\begin{array}{l}\text { Semester } \\
\text { II }\end{array}$ & $\begin{array}{c}\text { Semester } \\
\text { I }\end{array}$ & $\begin{array}{l}\text { Semester } \\
\text { II }\end{array}$ \\
\hline 1 & $\begin{array}{l}\text { Konservasi dan } \\
\text { pengelolaan } \\
\text { lingkungan }\end{array}$ & $\sqrt{ }$ & $\sqrt{ }$ & - & - & $\sqrt{ }$ & $\sqrt{ }$ \\
\hline 2 & $\begin{array}{l}\text { Tindakan konsumen } \\
\text { dan ekonomi }\end{array}$ & - & - & - & - & - & $\sqrt{ }$ \\
\hline 3 & $\begin{array}{l}\text { Persuasi antar pribadi } \\
\text { dan publik }\end{array}$ & - & - & - & - & - & - \\
\hline 4 & $\begin{array}{l}\text { Tindakan pemerintah } \\
\text { dan politik }\end{array}$ & - & - & - & - & $\sqrt{ }$ & - \\
\hline 5 & $\begin{array}{l}\text { Tindakan dan } \\
\text { penegakkan hukum }\end{array}$ & - & - & - & - & - & - \\
\hline 6 & $\begin{array}{l}\text { Bentuk partisipasi } \\
\text { warga negara }\end{array}$ & - & - & - & - & - & - \\
\hline
\end{tabular}

\section{Komponen Pengetahuan Ekologi dan Sejarah Alam}

Analisis yang dilakukan menunjukkan hasil bahwa sub-komponen dari komponen pengetahuan ekologi dan sejarah alam sudah ada hampir di semua buku, kecuali sub-komponen sejarah fisik dan biologi yang sedikit mendapat perhatian yaitu hanya terdapat pada buku kelas VII semester II dan IX semester II. Adapun integrasi komponen pengetahuan ekologi dan sejarah alam dalam buku teks pelajaran IPA SMP Kurikulum 2013 Terbitan Kemendikbud terdapat pada deskripsi materi, aktivitas, tugas dan gambar.

Perhatian yang besar diberikan pada komponen pengetahuan ekologi dan sejarah alam, baik pada buku Kelas VII, VIII maupun IX walaupun masih terdapat sub-komponen yang tidak terintegrasi. Komponen ini juga mendapat perhatian pada buku IPA sesuai dengan hasil penelitian Erdogan, Kostova \& Marcinkowski (2009) di Bulgaria dan Turki yang menunjukkan semua sub-komponen hampir semua terintegrasi. Selain itu sesuai juga dengan hasil penelitian Srbinovski, Erdogan \& Ismaili (2010) di Makedonia dan Turki serta Karimzadegan \& Meiboudi (2012) di Iran yang menunjukkan bahwa sub-komponen spesies dan populasi serta habitat dan lingkungan cenderung mendapat perhatian yang besar.

Materi pada buku IPA SMP yang banyak terdapat komponen pengetahuan ekologi dan sejarah alam adalah konsep ekosistem, karena mempelajari komponen-komponen ekosistem yang erat kaitannya dengan lingkungan. Hal tersebut sesuai dengan hasil penelitian yang menyebutkan bahwa pondasi utama pengetahuan ekologi adalah konsep ekosistem (Suhardin, 2016). Konsep ekosistem memperkuat pengetahuan mengenai konsep-konsep dasar ekologi. Hal tersebut didukung dengan hasil penelitian dimana pengetahuan ekologi yang dimiliki siswa, dapat menjadi landasan ekologi untuk dapat mengambil keputusan yang bijak sehubung dengan masalah lingkungan. Oleh karena itu dalam kurikulum perlu memuat komponen konseptual diantaranya konsep ekosistem dan implikasi ekologis dari aktivitas manusia (Hungerford, 1980; Srbinovski, et al., 2010).

\section{Komponen Pengetahuan Masalah dan Isu Lingkungan}

Analisis yang dilakukan menunjukkan hasil bahwa sub-komponen dari komponen pengetahuan masalah dan isu lingkungan sudah terdapat hampir di semua buku. Sub-komponen risiko, toksikologi dan kesehatan manusia, serta efek dari masalah dan isu, terdapat pada buku kelas VII, VIII dan IX. Sub-komponen masalah biofisik, penyebab masalah, penyebab isu, serta solusi dan tindakan alternatif terdapat pada buku kelas VII dan IX. Adapun sub-komponen bencana alam hanya terdapat pada buku kelas VII semester II, sedangkan sub-komponen isu sosial politik tidak terintegrasi sama sekali. Hal 
tersebut karena sub-komponen isu sosial politik terkait dengan ilmu sosial, yang kemungkinan lebih teramati di dalam studi sosial. Komponen pengetahuan masalah dan isu lingkungan dalam buku teks pelajaran IPA SMP Kurikulum 2013 terdapat pada deskripsi materi, aktivitas, tugas dan gambar.

Komponen pengetahuan masalah dan isu lingkungan juga mendapat perhatian pada buku IPA sesuai dengan hasil penelitian Erdogan, Kostova \& Marcinkowski (2009) di Bulgaria dan Turki, Srbinovski, Erdogan \& Ismaili (2010) di Makedonia dan Turki serta Karimzadegan \& Meiboudi (2012) di Iran.

Adapun materi IPA SMP yang paling banyak terdapat komponen pengetahuan masalah dan isu lingkungan adalah materi yang memuat konsep pencemaran lingkungan dan pemanasan global. Pengetahuan masalah dan isu lingkungan bertujuan untuk mendapatkan pemahaman mendasar mengenai masalah dan isu-isu lingkungan. Hasil penelitian menyatakan bahwa pengetahuan tentang isu lingkungan yang dimiliki seseorang seperti perubahan iklim dapat mempengaruhi perilaku kesadaran terhadap lingkungan (E.M. Dijkstra \& M.J. Goedhart, 2016; Fatria, 2017). Besarnya pengaruh pengetahuan tentang isu perubahan iklim terhadap kesadaran dan perilaku pro lingkungan, maka dari itu untuk meningkatkannya perlu mengembangkan pengetahuan tentang isu lingkungan (Simanjuntak, 2016), salah satu caranya adalah dengan mengintegrasikan konten isu lingkungan di dalam buku IPA SMP.

\section{Pengetahuan Sosial-Politik-Ekonomi}

Analisis yang dilakukan menunjukkan hasil bahwa hanya beberapa sub-komponen dari komponen pengetahuan sosial-politik-ekonomi yang terdapat di beberapa buku. Sub-komponen sistem sosial masyarakat dan partisipasi masyarakat terdapat pada buku kelas VII dan IX, sedangkan sub-komponen nilai dan kegiatan ekonomi serta pola geografi hanya terdapat pada buku kelas VII semester II. Sementara itu, subkomponen yang tidak terdapat pada buku IPA SMP Kurikulum 2013 Terbitan Kemendikbud adalah sub-komponen nilai dan kegiatan budaya serta sistem pemerintahan dan politik. Adapun integrasi komponen pengetahuan sosial-politikekonomi dalam buku teks pelajaran IPA SMP terdapat pada deskripsi materi, tugas dan gambar.

Komponen pengetahuan sosial-politikekonomi mendapat perhatian pada beberapa subkomponen sedangkan sub-komponen lainnya cenderung diabaikan, baik pada buku Kelas VII, VIII maupun IX. Komponen ini juga tidak mendapat perhatian di beberapa sub-komponen pada buku IPA sesuai dengan hasil penelitian Erdogan, Kostova \& Marcinkowski (2009) di Bulgaria dan Turki, khususnya pada subkomponen nilai dan kegiatan ekonomi, sistem pemerintahan dan politik serta pola geografi, karena sub-komponen ini lebih dominan dibahas pada mata pelajaran ilmu sosial. Namun, subkomponen sistem sosial masyarakat pada buku IPA SMP Kurikulum 2013 Terbitan Kemendikbud mendapat atensi karena terdapat di beberapa buku pada kelas yang berbeda, hal tersebut sesuai dengan hasil penelitian Karimzadegan \& Meiboudi (2012) di Iran, yaitu menunjukkan bahwa komponen ini cukup mendapat atensi dibanding sub-komponen lainnya dari komponen pengetahuan sosialpolitik-ekonomi.

Materi IPA SMP yang banyak terdapat komponen pengetahuan sosial-politik-ekonomi adalah materi yang memuat konsep energi, pencemaran lingkungan dan pemanasan global. Berdasarkan hal tersebut, dapat dipahami jika ada keterkaitan antara aspek sosial, politik dan ekonomi dengan lingkungan. Hal ini didukung dengan pernyataan bahwa konsep ketergantungan aspek ekonomi, sosial dan politik dengan ekologi, seperti kegiatan eksploitasi lingkungan untuk mencukupi kebutuhan hidup menjadi pengetahuan untuk bisa memberikan respon terhadap masalah lingkungan baik yang sifatnya potensial atau aktual (Hollweg, 2011).

\section{Komponen Keterampilan Kognitif}

Analisis yang dilakukan menunjukkan hasil bahwa sub-komponen dari komponen keterampilan kognitif sudah terdapat hampir di semua buku. Sub-komponen keterampilan pengumpulan data, keterampilan analisis data, dan keterampilan bertindak terdapat pada buku kelas VII, VIII dan IX, sedangkan keterampilan mengidentifikasi masalah dan isu, dan keterampilan analisis isu hanya terdapat pada 
buku kelas VII dan IX karena buku kelas VIII banyak membahas tentang sistem dalam tubuh manusia, yang tidak berkaitan langsung dengan konten lingkungan. Sementara itu, subkomponen keterampilan bertanya kurang mendapat perhatian, yaitu hanya terdapat pada buku kelas VII saja.

Komponen keterampilan kognitif mendapat cukup perhatian pada buku IPA SMP Kurikulum 2013 Terbitan Kemendikbud. Komponen ini juga mendapat perhatian sesuai dengan hasil penelitian Erdogan, Kostova \& Marcinkowski (2009) di Bulgaria dan Turki, Srbinovski, Erdogan \& Ismaili, (2010) di Makedonia dan Turki serta Karimzadegan \& Meiboudi (2012) di Iran. Namun sub-komponen dari komponen keterampilan kognitif tidak semua mendapat perhatian yang sama. Sub-komponen keterampilan bertanya kurang mendapat perhatian, karena hanya terdapat pada buku kelas VII semester II. Keterampilan bertanya menjadi penting adalah karena merupakan dasar untuk membangun keterampilan siswa dalam memberikan solusi alternatif dari suatu permasalahan (Ramadhan, dkk., 2017). Kegiatan bertanya akan menjadikan kebiasaan bagi siswa untuk spontan berpikir, cepat dan sigap dalam menanggapi suatu permasalahan (Pratiwi, dkk., 2019).

Sub-komponen keterampilan bertindak mendapat perhatian yang baik pada buku teks pelajaran IPA SMP Kurikulum 2013 Terbitan Kemendikbud. Integrasi sub-komponen keterampilan bertindak didominasi oleh sajian yang meminta siswa untuk memanfaatkan teknologi informasi, mempresentasikan hasil percobaan dan diskusi. Hal ini sesuai dengan hasil penelitian Yusefni (2016) yang menyebutkan bahwa keterampilan komunikasi mendukung siswa dalam proses transfer ilmu agar tidak ada kesalahpahaman dalam memahami informasi. Menurut Ramadhani, dkk., (2019) kegiatan presentasi dapat melatih siswa untuk bertukar pikiran dengan teman sejawat atapun guru mengenai hasil penelitian sederhana maupun diskusi kelompok.

Materi IPA SMP yang paling banyak terdapat komponen keterampilan kognitif adalah materi ekosistem, pencemaran lingkungan dan pemanasan global. Keterampilan kognitif yang ditemukan pada buku kelas VII, VIII dan IX tidak berdiri sendiri, melainkan berhubungan dengan komponen pengetahuan ekologi, pengetahuan masalah dan isu lingkungan dan pengetahuan sosial-politik-ekonomi. Hal ini sesuai dengan hasil penelitian Erdogan, Kostova \& Marcinkowski (2009), bahwa keterampilan kognitif melibatkan minat pada pengetahuan lingkungan, yang paling baik dikembangkan dengan memecahkan masalah lingkungan yang nyata.

\section{Komponen Afeksi dan Faktor-Faktor Yang Mempengaruhi Perilaku Bertanggung Jawab Terhadap Lingkungan}

Komponen afeksi dan faktor-faktor yang mempengaruhi perilaku bertanggung jawab terhadap lingkungan mendapat perhatian yang kecil dalam buku IPA SMP. Sub-komponen kepekaan dan kepedulian terhadap lingkungan dan sikap lingkungan hanya terdapat pada buku kelas VIII dan IX, sedangkan sub-komponen nilai-nilai lingkungan, pertimbangan etika dan moral, lokus kendali, tanggung jawab pribadi, serta kemauan/motivasi/niat untuk bertindak tidak terintegrasi dalam buku teks pelajaran IPA SMP Terbitan Kemendikbud. Adapun integrasi komponen afeksi dan faktor-faktor yang mempengaruhi perilaku bertanggung jawab terhadap lingkungan, dalam buku teks pelajaran IPA SMP terdapat pada deskripsi materi, tugas dan gambar.

Sub-komponen kepekaan dan kepedulian terhadap lingkungan, sikap lingkungan dan tanggung jawab pribadi, kurang mendapat perhatian pada buku IPA SMP Kurikulum 2013 Terbitan Kemendikbud, yang juga sesuai dengan hasil penelitian Erdogan, Kostova \& Marcinkowski (2009) di Turki, dimana hampir semua sub-komponen tidak mendapat perhatian kecuali sub-komponen kepekaan dan kepedulian terhadap lingkungan. Hasil penelitian Karimzadegan \& Meiboudi (2012) di Iran, juga menunjukkan bahwa hanya sub-komponen tanggung jawab pribadi yang mendapat perhatian. Hasil penelitian pada buku IPA SMP Kurikulum 2013 Terbitan Kemendikbud ini juga didukung oleh hasil penelitian Srbinovski, Erdogan \& Ismail (2010) di Makedonia dan Turki, yang menyatakan bahwa komponen afeksi dan faktor-faktor yang mempengaruhi perilaku bertanggung jawab terhadap lingkungan bersama dengan komponen perilaku 
bertanggung jawab terhadap lingkungan kurang mendapat perhatian.

Hasil penelitian menunjukkan hanya subkomponen kepekaan dan kepedulian terhadap lingkungan dan sikap lingkungan yang mendapat cukup perhatian, padahal buku teks pelajaran IPA harus optimal dalam menyadarkan siswa akan pentingnya lingkungan. Peka, peduli dan sikap lingkungan yang diorientasikan dalam buku teks pelajaran IPA merupakan salah satu alternatif untuk memberikan kesadaran pada siswa agar memiliki kepedulian terhadap lingkungan. Namun, berbeda dengan subkomponen nilai-nilai lingkungan yang mendapat sedikit perhatian. Padahal, buku teks pelajaran IPA yang memberikan ruang pada nilai-nilai lingkungan akan membentuk karakter peduli lingkungan. Hal tersebut diperkuat dengan pernyataan Gumelar (2016) yaitu dimana nilainilai lingkungan menjadi penting karena siswa dapat memiliki pemahaman tentang keterkaitan manusia dengan ekosistem, yang mengartikan bahwa manusia berpengaruh secara substansial pada lingkungan. Sub-komponen lokus kendali hanya mendapat atensi pada buku IPA kelas VII semester II. Sedangkan menurut Putri (2017) adanya lokus kendali tentang keberlanjutan lingkungan bersama cara pandang siswa dapat membangun pemahaman siswa tentang urgensi menjaga dan mengelola lingkungan.

\section{Komponen Perilaku Bertanggung Jawab Terhadap Lingkungan}

Komponen perilaku bertanggung jawab terhadap lingkungan mendapat perhatian yang kecil dalam buku IPA SMP Terbitan Kemendikbud. Sub-komponen konservasi dan pengelolaan lingkungan hanya terdapat pada buku kelas VII dan IX. Adapun sub-komponen tindakan ekonomi hanya terdapat pada buku kelas IX semester II, sedangkan sub-komponen tindakan pemerintah dan politik hanya terdapat pada buku kelas IX semester I. Sub-komponen yang tidak terdapat sama sekali dalam buku IPA SMP adalah tindakan persuasi antar pribadi dan publik, tindakan dan penegakan hukum, dan bentuk partisipasi warga Negara. Adapun komponen perilaku bertanggung jawab terhadap lingkungan dalam buku teks pelajaran IPA SMP terdapat pada deskripsi materi, aktivitas, tugas dan gambar.
Komponen perilaku bertanggung jawab terhadap lingkungan kurang mendapat perhatian, baik pada buku Kelas VII, VIII maupun IX. Komponen ini juga kurang mendapat perhatian sesuai dengan hasil penelitian Erdogan, Kostova \& Marcinkowski (2009) di Bulgaria dan Turki, khususnya pada sub-komponen tindakan ekonomi, tindakan persuasi antar pribadi dan publik dan partisipasi warga Negara, karena subkomponen ini lebih dominan dibahas pada mata pelajaran ilmu sosial dan hanya beberapa yang terintegrasi. Hasil penelitian Srbinovski, Erdogan \& Ismaili (2010) di Makedonia dan Turki, serta Karimzadegan \& Meiboudi (2012) di Iran, juga menunjukkan bahwa komponen ini bersama dengan komponen faktor-faktor yang mempengaruhi perilaku bertanggung jawab terhadap lingkungan cenderung kurang mendapat perhatian dibanding komponen literasi lingkungan lainnya, khususnya dibandingkan dengan komponen pengetahuan ekologi dan sejarah alam.

Hasil penelitian menunjukkan komponen perilaku bertanggung jawab terhadap lingkungan kurang mendapat perhatian. Terdapat beberapa faktor yang mempengaruhi sedikitnya perhatian yang diberikan seperti kebijakan pemerintah yang tertuang dalam Peraturan Menteri Pendidikan dan Kebudayaan No.4 Tahun 2018 tentang Penilaian Hasil Belajar oleh Satuan Pendidikan dan Penilaian Hasil Belajar, dimana salah satu poinnya menjelaskan bahwa Ujian Nasional (UN) sebagai Standar Penilaian Hasil belajar untuk menilai pencapaian kompetensi lulusan secara nasional yang mengacu pada Standar Kompetensi Lulusan, yang mana poin tersebut menekankan penilaian pada domain pengetahuan, sehingga materi yang terdapat pada buku teks pelajaran IPA SMP juga lebih menekankan pada ranah pengetahuan.

Selain itu, faktor lain yang mempengaruhi komponen perilaku bertanggung jawab terhadap lingkungan sedikit mendapat perhatian karena kebijakan pemerintah adalah prosedur pembelajaran semua mata pelajaran yang sesuai Kurikulum 2013, termasuk mata pelajaran IPA berpendekatan ilmiah yaitu untuk mendukung manusia yang memiliki sikap ilmiah (Kusmana, 2017).

Berdasarkan hasil analisis di atas, masih banyak peluang yang dapat dilakukan untuk 
mengintegrasikan komponen literasi lingkungan pada konten buku IPA SMP Kurikulum 2013 Terbitan Kemendikbud, seperti menambahkan deskripsi materi, gambar, tugas maupun aktivitas. Literasi lingkungan penting dimiliki siswa karena dapat meningkatkan kemampuan belajar dan kualitas hidup sepanjang hayat (Komariah, 2017). Meilinda, et al., (2017) menyatakan seseorang yang peduli dengan lingkungannya maka akan bertindak terhadap isu-isu lingkungan. Seseorang yang sadar akan lingkungan memiliki pengetahuan, sikap, keterampilan, motivasi dan komitmen yang mampu memberikan solusi dan pencegahan akan kerusakan lingkungan.

\section{KESIMPULAN}

Hasil analisis menunjukkan bahwa komponen literasi lingkungan belum tercakup dengan baik dalam buku teks pelajaran IPA SMP Kurikulum 2013 Terbitan Kemendikbud Kelas VII, VIII dan IX karena tidak semua mendapat perhatian yang sama. Komponen yang mendapat perhatian adalah pengetahuan ekologi dan sejarah alam, pengetahuan masalah dan isu lingkungan, dan keterampilan kognitif. Adapun komponen-komponen lainnya yang kurang mendapat perhatian yaitu komponen pengetahuan sosial-politik-ekonomi, afeksi dan faktor-faktor yang mempengaruhi perilaku bertanggung jawab terhadap lingkungan, dan perilaku bertanggung jawab terhadap lingkungan, masih dapat dikembangkan dengan mengintegrasikan konten-konten lingkungan ke dalam bab-bab yang ada pada buku teks pelajaran IPA SMP Kurikulum 2013 Terbitan Kemendikbud Kelas VII, VIII dan IX.

\section{DAFTAR PUSTAKA}

Erdogan, M., Kostova, Z., \& Marcinkowski, T. (2009). Components of Environmental Literacy in Elementary Science Education Curriculum in Bulgaria and Turkey. Eurasia Journal Mathematics, Science and Technology Education, 5(1), 15-26.

Fatria, E. (2017). Relationship Between Knowledge About Climate Change Issues and Locus of Control with Students Citizenship Behaviour. Jurnal Pendidikan Lingkungan dan
Pembangunan Berkelanjutan, 18(1), 3642.

Gumelar, G. (2016). Nilai Lingkungan dan Sikap Ramah Lingkungan Pada Warga Jakarta di Pemukiman Kumuh. Jurnal Psikologi, 12(1), 222.

Herlanti, Y. (2016). Pengembangan Kurikulum Pendidikan Lingkungan di Kota Tangerang . Proceeding Biology Education Conference, (pp. 52-57). Semarang.

Hollweg, K. S. (2011). Developing a Framework for Assesing Environmental Literacy. Washington: North American Assosiation for Environmental Education.

Karimzadegan, H., \& Meiboudi, H. (2012). Exploration of Environmental Literacy in Science Education. Procedia - Social and Behavioral Sciences, 404-409.

Komariah, N., Yusup, P. M., Saepudin, E., \& Rodiah, S. (2017). Pendidikan Literasi Lingkungan Sebagai Penunjang Desa Wisata Agro Kecamatan Padaherang Kabupaten Pangandaran. Dharmakarya: Jurnal Aplikasi Ipteks untuk Masyarakat, 6(2), 111-115.

Kusmana , S. (2017). Pengembangan Literasi dalam Kurikulum Pendidikan Dasar dan Menengah. Diglosia - Jurnal Pendidikan, Kebahasaan dan Kesusastraan Indonesia, 1(1), 54.

Kusumaningrum, D. (2018). Literasi Lingkungan dalam Kurikulum 2013 dan Pembelajaran IPA di SD. Indonesian Journal of Natural Science Education (IJNSE), 1(2), 57-64.

Meilinda, H., Prayitno , B. A., \& Karyanto, P. (2017). Student's Environmental Literacy Profile of Adiwiyata Green School in Surakarta, Indonesia. Journal of Education and, 11(3), 299-306.

Peraturan Menteri Pendidikan dan Kebudayaan No.4 Tahun 2018 tentang Penilaian Hasil Belajar

Pratiwi, D. I., Kamilasari, N. W., Nuri, D., \& Supeno. (2019). Analisis Keterampilan Bertanya Siswa Pada Pembelajaran IPA Materi Suhu dan Kalor dengan Model Problem Based Learning di SMP Negeri 
2 Jember. Jurnal Pembelajaran Fisika, 8(4), 269-274.

Putri, M. K. (2016). Hubungan Antara Pengetahuan Siswa tentang Konsep Ekosistem dan Locus of Control dengan Cara Pandang Siswa tentang Sustainable Society (Studi Korelasional di SMA Negeri 1 Palembang). Jurnal Swarnabhumi, 1(1), 22-28.

Rahmah, S., Puspitasari, R., Lubis, R., \& Festiyed. (2019). Analisis Buku Ajar IPA SMP Kelas VIII Berdasarkan Pada Literasi Lingkungan. Pillar of Physics Education, 12(3), 601-608.

Ramadhan, F., Mahanal, S., \& Zubaidah, S. (2017). Kemampuan Bertanya Siswa Kelas X SMA Swasta Kota Batu Pada Pelajaran Biologi. Jurnal Pendidikan Biologi, 8(1), 11-15.

Ramadhani, P. R., Akmam, Desnita, \& Darvina, Y. (2019). Analisis Keterampilan Proses Sains Pada Buku Teks Pelajaran Fisika SMA Kelas XI Semester I. Pillar of Physics Education, 12(4), 649-656.

Reis, G., Guimaraes-Iosif, R., \& Reis, J. (2009). Media and Environmental Literacy: Making School Relevant. Leituras Transdisciplinares de Telas e Textos, 5(9), 26-40.

Setyowati. (2014). Pendidikan Lingkungan Hidup : Buku Ajar MKU Lingkungan Hidup. Semarang: Pusbang Mata Kuliah Umum Universitas Negeri Semarang.
Simanjuntak, P. M. (2016). Perilaku Bertanggung Jawab Lingkungan Siswa. Indonesian Journal of Environmental Education and Manajemen, 1(2), 64.

Srbinovski, M., Erdogan, M., \& Ismaili, M. (2010). Environmental Literacy in The Science Education Curriculum in Macedonia and Turkey. Procedia Social and Behavioral Sciences, 2(2), 45284532.

Suhardin. (2015). Pengaruh Perbedaan Jenis Kelamin dan Pengetahuan tentang Konsep Dasar Ekologi Terhadap Kepedulian Lingkungan. Jurnal Penelitian Pendidikan Agama dan Keagamaan, 14(1), 121.

Tuncer, G., Tekkaya, C., Sungur, S., \& Cakiroglu, J. (2009). Assesing PreService Teachers Environmental Literacy in Turkey as a Mean to Develop Teacher Education Programs. International Journal of Education Development, 29(4), 426-436.

Yusefni, W., \& Sriyati, S. (2016). Pembelajaran IPA Terpadu Menggunakan Pendekatan Science Writing Heuristic Untuk Meningkatkan Kemampuan Komunikasi Tulisan Siswa SMP. Edusains, 8(1), 1017.

Zulfa, V., Max, M., Hukum, I., \& Ilyas, I. (2016). Isu-Isu Kritis Lingkungan dan Perspektif Global. Jurnal Green Growth dan Manajemen Lingkungan, 5(1), 2940. 